\title{
Muscle-specific deletion of SOCS3 increases the early inflammatory response but does not affect regeneration after myotoxic injury
}

Kristy Swiderski, Savant S. Thakur, Timur Naim, Jennifer Trieu, Annabel Chee, David I. Stapleton, René Koopman and Gordon S. Lynch*

\begin{abstract}
Background: Muscles of old animals are injured more easily and regenerate poorly, attributed in part to increased levels of circulating pro-inflammatory cytokines. The Janus kinase/signal transducers and activators of transcription (JAK/STAT) signaling cascade is a key mediator of inflammatory cytokine action, and signaling via this pathway is increased in muscles with aging. As a negative regulator of JAKJSTAT signaling, a key mediator of myogenic proliferation and differentiation, altered expression of suppressor of cytokine signaling (SOCS3) is likely to have important consequences for muscle regeneration. To model this scenario, we investigated the effect of SOCS3 deletion within mature muscle fibers on injury and repair. We tested the hypothesis that reduced SOCS3 function would alter the inflammatory response and impair muscle regeneration after myotoxic injury.

Methods: Mice with a specific deletion of SOCS3 within mature skeletal muscle fibers were used to assess the effect of SOCS3 deletion on muscle injury and repair. Twelve-week-old or 24-month-old SOCS3 muscle-specific knockout (SOCS3 MKO) mice and littermate controls were either left uninjured or injured with a single injection of notexin $(10 \mu \mathrm{g} / \mathrm{ml})$ into the right tibialis anterior (TA) muscle. At 1, 2, 3, 5, 7, or 14 days post-injury, the right TA muscle was excised and subjected to histological, western immunoblotting, and gene expression analyses. Force production and fatigue were assessed in uninjured muscles and at 7 days post-notexin injury.

Results: In uninjured muscles, SOCS3 deletion decreased force production during fatigue but had no effect on the gross or histological appearance of the TA muscles. After notexin injury, deletion of SOCS3 increased STAT3 phosphorylation at day 1 and increased the mRNA expression of the inflammatory cytokine TNF- $a$, and the inflammatory cell markers F4/80 and CD68 at day 2. Gene expression analysis of the regeneration markers Pax7, MyoD, and Myogenin indicated SOCS3 deletion had no effect on the progression of muscle repair after notexin injury. Inflammation and regeneration were also unchanged in the muscles of 24-month-old SOCS3 MKO mice compared with control.

Conclusions: Loss of SOCS3 expression in mature muscle fibers increased the inflammatory response to myotoxic injury but did not impair muscle regeneration in either adult or old mice. Therefore, reduced SOCS3 expression in muscle fibers is unlikely to underlie impaired muscle regeneration. Further investigation into the role of SOCS3 in other cell types involved in muscle repair is warranted.
\end{abstract}

Keywords: SOCS3, Muscle, Regeneration, Inflammation, MCK

\footnotetext{
* Correspondence: gs|@unimelb.edu.au

Basic and Clinical Myology Laboratory, Department of Physiology, The

University of Melbourne, Melbourne 3010, Australia
} 


\section{Background}

Muscles of old animals are more susceptible to injury and regenerate poorly. Cycles of repeated damage and incomplete repair contributes to muscle atrophy and weakness with age [1-5]. A well-regulated inflammatory response is critical for the initiation of muscle repair through muscle stem cell activation and necessary for myogenic differentiation [6-11]. In contrast, chronic low-grade systemic inflammation is thought to interfere with effective regeneration in older individuals. Although increased levels of circulating pro-inflammatory cytokines, such as interleukin -6 (IL-6), interferon- $\gamma$ (IFN- $\gamma$ ), and tumor necrosis factor- $\alpha$ (TNF- $\alpha$ ) are associated with muscle wasting and are increased in aged muscle [12], the signaling mechanisms controlling degeneration, regeneration, and inflammation are not well understood.

Inflammatory cytokines exert many effects via activation of the Janus kinase/Signal transducers and activators of transcription (JAK/STAT) signaling pathway [13]. The suppressors of cytokine signaling (SOCS) protein family consisting of eight members including cytokine-induced STAT inhibitor (CIS) and SOCS1-7 are key negative regulators of JAK/STAT signaling. SOCS3 is one of the best characterized SOCS proteins and an important regulator of JAK1/STAT3 signaling and inflammation in many cell types via direct interactions with both the gp130 receptor and JAK1 [14-17]. Properly regulated JAK/STAT signaling is required for progression through myogenic differentiation and critical for muscle regeneration [18].

In the absence of inflammation, SOCS3 is expressed at very low levels but is thought to play a role in various muscle resident cells including hematopoietic cells, muscle stem cells, and mature muscle fibers [17, 19-23]. In vitro adenoviral overexpression of SOCS3 in human myotubes indicated a role for SOCS3 in directing the expression of genes regulating myogenic differentiation, myotube maturation, and cell survival [24], demonstrating a potential role for SOCS3 in regulating myogenesis. Transgenic muscle-specific overexpression of SOCS3, driven by the myosin light chain (MLC) promoter, impairs muscle morphology and ambulation, associated with disrupted calcineurin signaling and defects in sarcoplasmic reticulum and mitochondrial function [25]. In another study, transgenic overexpression of SOCS3 driven by the muscle creatine kinase (MCK) promoter impaired glucose and insulin tolerance as a result of suppressed leptininduced activation of the AMP-regulated protein kinase (AMPK) [23]. In contrast, mice with MCK-Cre-mediated SOCS3 deletion had normal muscle development and functional performance and, consistent with a role of SOCS3 in inhibition of insulin signaling, had improved insulin sensitivity and glucose homeostasis [26].

As JAK/STAT signaling is implicated in the regulation of inflammation, anabolic signaling, and myogenic differentiation, altered regulation of this signaling is likely to have important consequences for muscle health and effective regeneration. Increased STAT3 phosphorylation and SOCS3 messenger RNA (mRNA) expression has been reported in skeletal muscles from old compared with young rats [27]. SOCS3 gene and protein levels were increased in human skeletal muscle biopsies obtained from older participants ( $70 \pm 0.3$ years) compared to healthy young adults ( $20 \pm 0.2$ years) at rest [28]. However, in a different study, STAT3 activation was increased and SOCS3 protein decreased in skeletal muscle biopsies obtained from older adults compared with younger adults $2 \mathrm{~h}$ after a bout of resistance exercise [29]. Interestingly, mRNA levels of SOCS3 were higher in skeletal muscle biopsies obtained from older adults compared with young adults at this time, indicating either an issue with SOCS3 protein translation or a delay in the signaling pathway in muscles from older adults [29].

Studies testing the hypothesis that altered SOCS3 expression and inflammatory JAK/STAT signaling contributes to impaired muscle regeneration have produced conflicting results, but a common theme is an age-related increase in STAT3 signaling in skeletal muscle which suggests impaired negative regulation of JAK/STAT signaling by SOCS3 $[27,29]$. Reduced SOCS3 function could contribute to impaired muscle regeneration and chronic inflammation with aging. To model this scenario, we investigated the effect of SOCS3 deletion, specifically within mature muscle fibers, on injury and repair. Since SOCS3 is expressed in multiple cell types involved in the repair of muscle after injury (including muscle fibers, stem cells, and inflammatory cells), it is important to determine in which cell population reduced SOCS3 expression contributes to impaired muscle regeneration. We tested the hypothesis that reduced SOCS3 function would alter the inflammatory response and impair muscle regeneration after myotoxic injury.

\section{Methods \\ Cell culture}

C2C12 cells (obtained from ATCC, Manassas, VA, USA) were maintained as proliferating myoblasts in culture at $37{ }^{\circ} \mathrm{C}+5 \% \mathrm{CO}_{2}$ in DMEM/10 \% FBS/1 \% L-glutamine and sub-cultured at 60-70\% confluency. For treatment of proliferating myoblasts, $\mathrm{C} 2 \mathrm{C} 12$ cells were seeded into six-well tissue culture plates and grown to $50-70 \%$ confluency over $48 \mathrm{~h}$. Cells were either left unstimulated (0) or stimulated with $100 \mathrm{ng} / \mathrm{mL}$ recombinant murine $(\mathrm{rm})$ IL-6 (kindly provided by Prof. Warren Alexander, The Walter and Eliza Hall Institute, Melbourne, Australia), $100 \mathrm{ng} / \mathrm{mL} \mathrm{rm}$ IFN- $\gamma$ (R\&D Systems Inc., MN, USA), or $10 \mathrm{ng} / \mathrm{mL} \mathrm{rm}$ TNF- $\alpha$ (R\&D Systems Inc.) in DMEM/ $10 \% \mathrm{FBS} / 1 \% \mathrm{~L}$-glutamine for $0.25,0.5,1,2$, or $4 \mathrm{~h}$ at $37{ }^{\circ} \mathrm{C} \pm 5 \% \mathrm{CO}_{2}$. For treatment of differentiated 
myotubes, $\mathrm{C} 2 \mathrm{C} 12$ cells were seeded into six-well tissue culture plates and grown to $100 \%$ confluency over $48 \mathrm{~h}$ at $37{ }^{\circ} \mathrm{C} \pm 5 \% \mathrm{CO}_{2}$ in DMEM/10 \% FBS/1 \% L-glutamine. Once confluent, media were replaced with DMEM/ $2 \% \mathrm{HS} / 1 \% \mathrm{~L}$-glutamine to induce myotube differentiation. Media were changed every $48 \mathrm{~h}$. On day 5 of differentiation, cells were either left unstimulated (0) or stimulated with $100 \mathrm{ng} / \mathrm{mL} \mathrm{rm} \mathrm{IL-6,} 100 \mathrm{ng} / \mathrm{mL}$ $\mathrm{rm}$ IFN- $\gamma$, or $10 \mathrm{ng} / \mathrm{mL} \mathrm{rm}$ TNF- $\alpha$ in DMEM $/ 2 \%$ $\mathrm{HS} / 1 \%$ L-glutamine for $0.25,0.5,1,2$, or $4 \mathrm{~h}$ at $37^{\circ}$ $\mathrm{C} \pm 5 \% \mathrm{CO}_{2}$. Fresh cell culture media was not added on the day of stimulation to avoid activation of signaling pathways via addition of fresh serum.

\section{Animals}

$\mathrm{SOCS}^{\mathrm{f}}{ }^{\mathrm{f} l \mathrm{l}}$ MCK-Cre mice were obtained from Prof. Gregory Steinberg (St Vincent's Institute, Melbourne, Australia) and bred and maintained in the Biological Research Facility (BRF) at The University of Melbourne. Breeding was performed to generate animals heterozygous for Cre-recombinase expression $\left(\mathrm{SOCS}^{\mathrm{fl} / \mathrm{fl}} \mathrm{MCK}^{\mathrm{C}-\mathrm{Cre}^{+}}\right.$ mice) and Cre-negative littermate controls (SOCS3 ${ }^{\mathrm{fl} / \mathrm{fl}}$ MCK-Cre ${ }^{-}$mice). All experimental protocols were approved by the Animal Ethics Committee of The University of Melbourne and conducted in accordance with the Australian code of practice for the care and use of animals for scientific purposes as stipulated by the National Health and Medical Research Council (Australia).

To confirm SOCS3 gene deletion by genomic PCR, DNA was extracted from liver and skeletal muscle tissue from $\mathrm{SOCS}^{\mathrm{f} / / \mathrm{ll}} \mathrm{MCK}^{-\mathrm{Cre}^{+}}$and SOCS3 $3^{\mathrm{f} / \mathrm{fl}}$ MCK-Cre ${ }^{-}$mice using the GenElute genomic DNA miniprep (Sigma-Aldrich, St. Louis, MO, USA) as per manufacturer's instructions. Genomic PCR was performed using the following forward and reverse primer sequences: SOCS3, 5'-ACGTCTGTG ATGCTTTGCTG-3' and 5'-TCTTGTGTCTCTCCCCA TCC-3', under the following conditions: step $1-94{ }^{\circ} \mathrm{C}$ $3 \mathrm{~min}$, step $2-94{ }^{\circ} \mathrm{C} 30 \mathrm{~s}$, step $3-55^{\circ} \mathrm{C} 30 \mathrm{~s}$, step $4-72{ }^{\circ} \mathrm{C}$ $60 \mathrm{~s}$, cycle steps $2-4.36$ times, step $5-72{ }^{\circ} \mathrm{C} 5 \mathrm{~min}$.

To confirm SOCS3 deletion in muscle fibers, $\mathrm{SOCS}^{\mathrm{f} / \mathrm{fl}}$ $\mathrm{MCK}-C r e^{+}$and $\mathrm{SOCS}^{\mathrm{fl} / \mathrm{fl}}$ MCK-Cre ${ }^{-}$mice received an intraperitoneal injection (i.p.) of saline or lipopolysaccharide (LPS $1 \mathrm{mg} / \mathrm{kg}$; Sigma-Aldrich) and were killed $4 \mathrm{~h}$ postinjection. Gastrocnemius muscles were removed and snap frozen. Muscles were freeze-dried overnight and freed from visible adipose and connective tissue, and individual muscle fibers were dissected and placed into clean Eppendorf tubes. Total RNA was extracted using an RNeasy Fibrous Tissue Mini Kit (Qiagen, Venlo, Limburg, Netherlands) as per manufacturer's instructions. The concentration and quality of RNA samples were determined using Nanodrop 2000 spectrophotometer (Thermo Scientific, Waltham, MA, USA). Real-time RT-PCR was performed as described previously [30] using the following forward and reverse primer sequences: SOCS3, 5'-GCTGGCCAAAGAAATA ACCA-3' and 5' - AGCTCACCAGCCTCATCTGT-3'. Relative gene expression was calculated using the expression $2^{-\Delta \mathrm{CT}}$, normalized to total complementary DNA (cDNA) content as determined using Qubit 2.0 Fluorometer (Life Technologies, Carlsbad, CA, USA), as described previously [12].

\section{Myotoxic injury}

Twelve-week-old or 24-month-old male and female SOCS3 MKO (SOCS3 $\left.{ }^{\mathrm{fl} / \mathrm{fl}} \mathrm{MCK}-\mathrm{Cre}^{+}\right)$mice and their littermate controls (SOCS3 ${ }^{\mathrm{fl} / \mathrm{fl}} \mathrm{MCK}^{-\mathrm{Cre}^{-}}$mice) were anesthetized with an intraperitoneal injection (i.p.) of $100 \mathrm{mg} / \mathrm{kg}$ ketamine (Ceva Animal Health Pty. Ltd., Glenorlie, NSW, Australia) and $10 \mathrm{mg} / \mathrm{kg}$ xylazine (ilium xylazil-20; Troy Laboratories, Smithfield, NSW, Australia). Once non-responsive to tactile stimuli, the right tibialis anterior (TA) muscle was surgically exposed and injected with $40 \mu \mathrm{l}$ notexin $(10 \mu \mathrm{g} / \mathrm{ml}$ saline; Latoxan, Valence, France) to induce muscle fiber degeneration. After the intramuscular injection, the skin incision was closed with Michel clips (Aesculap, Tuttlingen, Germany), and the mouse allowed to recover on a heating pad. In 12-weekold mice, the right TA muscle was excised and weighed at $1,2,3,5,7$, or 14 days post-notexin injury. In 24-monthold mice, the right TA muscle was excised and weighed at 7 days post-notexin injury only. The right TA muscles were also excised from uninjured mice for use as controls. The right TA was cut transversely with one third immediately snap frozen in liquid nitrogen for RNA extraction and the remaining two thirds coated with optimal cutting temperature (OCT) compound (Tissue-Tek, Sakura Finetek, CA, USA) and frozen in thawing isopentane for histological analyses and western immunoblotting. All muscles were subsequently stored at $-80^{\circ} \mathrm{C}$.

\section{Assessment of contractile properties of skeletal muscle and tissue collection}

At 7 days post-notexin injury, both injured and uninjured mice were anesthetized with sodium pentobarbitone (Nembutal; $60 \mathrm{mg} / \mathrm{kg}$; Sigma-Aldrich) via i.p. injection. The methods for assessment of the contractile properties of the mouse tibialis anterior muscle in situ have been described in detail previously [31]. At the conclusion of the contractile measurements in situ, the right and left TA muscles were carefully excised, blotted on filter paper, weighed on an analytical balance, and frozen in thawing isopentane for later histological examination.

\section{Skeletal muscle histology}

Serial sections $(5 \mu \mathrm{m})$ were cut transversely through the TA muscle using a refrigerated $\left(-20^{\circ} \mathrm{C}\right)$ cryostat $(\mathrm{CTI}$ Cryostat; IEC, Needham Heights, MA). Sections were stained (or reacted) with hematoxylin and eosin (H\&E) 
to determine general muscle architecture, an antilaminin antibody (\#L9393; Sigma-Aldrich, St. Louis, MO, USA) for determination of mean myofiber CSA, or succinate dehydrogenase $(\mathrm{SDH})$ to determine activity of oxidative enzymes [32]. Optical density (OD) of SDH was determined after $6 \mathrm{~min}$ of reactivity for all samples, and SDH-reacted sections were captured in full color using bright-field light microscopy and analyzed, as described previously [31]. For histological assessments and analysis of right TA muscle CSA in aged mice, comparisons were made to a small number of older uninjured control and SOCS3 MKO mice aged between 17 and 24 months of age ( $n=5 /$ genotype). Digital images of stained sections were obtained using an upright microscope with camera (Axio Imager day 1, Carl Zeiss, Wrek, Göttingen, Germany), controlled by AxioVision AC software (AxioVision AC Rel. 4.8, Carl Zeiss Imaging Solutions, Wrek, Göttingen, Germany). Images were quantified using AxioVision 4.8.2 software.

\section{Skeletal muscle immunostaining}

Serial sections $(5 \mu \mathrm{m})$ were cut transversely through the TA muscle using a refrigerated $\left(-20{ }^{\circ} \mathrm{C}\right)$ cryostat $(\mathrm{CTI}$ Cryostat; IEC, Needham Heights, MA). Sections were fixed for $10 \mathrm{~min}$ in methanol at $-20{ }^{\circ} \mathrm{C}$, air-dried, and subsequently incubated with Alexa488- and Alexa647conjugated antibodies raised against F4/80 and CD68 (Abcam., Cambridge, UK), respectively, for $1 \mathrm{~h}$ at room temperature in a humidified chamber. Slides were rinsed for 5 min in PBS containing $0.05 \%$ Tween 20 (PBStw) and $2 \times 5 \mathrm{~min}$ in PBS and then incubated for $30 \mathrm{~min}$ with $4^{\prime}, 6$ diamindino-2-phenylindole (DAPI, $5 \mu \mathrm{g} / \mathrm{mL}$ PBS) to visualize nuclei. After washing with PBStw and PBS, the sections were embedded in $\mathrm{Mowiol}^{\circ}$ and covered with a coverslip. Digital images of stained sections were obtained using an upright microscope with camera (Axio Imager D1, Carl Zeiss, Wrek Göttingen, Germany), controlled by AxioVision AC software (AxioVision AC Rel. 4.8.2, Carl Zeiss Imaging Solutions, Wrek, Wrek Göttingen, Germany) as described previously.

\section{RNA extraction and qPCR}

Total RNA was extracted from each portion of right TA muscle ( $n=6 /$ genotype/time-point) using an RNeasy Fibrous Tissue Mini Kit (Qiagen, Venlo, Limburg, Netherlands) as per manufacturer's instructions. The concentration and quality of RNA samples was determined using Nanodrop 2000 spectrophotometer (Thermo Scientific, Waltham, MA, USA). Real-time RT-PCR was performed as described previously [30] using the following forward and reverse primer sequences: MCK, 5' ${ }^{\prime}$ CACCA TGCCGTTCGGCAACA- ${ }^{\prime}$ and $5^{\prime}$-GGTTGTCCACC CCAGTCT-3'; SOCS3, 5' -GCTGGCCAAAGAAATAACC A-3' and 5'-AGCTCACCAGCCTCATCTGT-3'; Pax7,
5'-GGAAAACCAGTGTGCCATCT-3' and 5'-CCTTGT CTTTGGCACCATTT-3'; MyoD, 5'-AGTGAATGAG GCCTTCGAGA-3' and 5'-GCATCTGAGTCGCCACT GTA-3'; Myogenin, 5'-CACTCCCTTACGTCCATCGT-3' and 5'-CAGGACAGCCCCACTTAAAA-3'; IL-6, 5'-CC GGAGAGGAGACTTCACAG-3' and 5'-TCCACGATTT CCCAGAGAAC-3'; TNF- $\alpha, 5^{\prime}$-GGCCTTCCTACCTTCA GACC-3' and 5 $^{\prime}$-AGCAAAAGAGGAGGCAACAA-3'; IFN- $\gamma, 5^{\prime}$-ACTGGCAAAAGGATGGTGAC-3' and $5^{\prime}-\mathrm{T}$ GAGCTCATTGAATGCTTGG-3'; F4/80, 5' -CATCAG CCATGTGGGTACAG-3' and 5'-CATCACTGCCTCC ACTAGCA-3'; CD68, 5'-TCCAAGCCCAAATTCAA ATC-3' and 5' -ATTGTATTCCACCGCCATGT-3'. Gene expression was quantified using a cycle threshold $\left(C_{T}\right)$ method. As myotoxic injury with notexin causes complete degradation of skeletal muscle fibers, normalizing mRNA to a housekeeping gene is difficult, and so relative gene expression was calculated using the expression $2^{-\Delta \mathrm{CT}}$, normalized to total cDNA content as determined using Qubit 2.0 Fluorimeter (Life Technologies, Carlsbad, CA, USA), as described previously [12].

\section{Antibodies}

The following primary antibodies were used throughout the experiments in $5 \%$ BSA/TBS/0.1 \% Tween-20: rabbit-anti-phosphorylated STAT1 (Y701) (Cell Signaling Technology, Danvers, MA, USA; 1:1000), mouse-antiSTAT1 (BD Biosciences, San Jose, CA, USA; 1:1000), rabbit-anti-phosphorylated STAT3 (Y705) (Cell Signaling Technology, 1:1000), rabbit-anti-STAT3 (Cell Signaling Technology, 1:1000), and rabbit-anti-SOCS3 (Immunobiological Laboratories Co. Ltd., Gunma, Japan; 1:200). Horseradish peroxidase (HRP)-conjugated donkey-antirabbit immunoglobulin (GE healthcare life sciences; Marlborough, MA, USA) secondary antibody was used at $1: 5000$ in $5 \%$ BSA/TBS/0.1 \% Tween-20. HRPconjugated sheep-anti-mouse immunoglobulin (GE Healthcare Life Sciences) secondary antibody was used at 1:5000 in $5 \% \mathrm{BSA} / \mathrm{TBS} / 0.1 \%$ Tween-20.

\section{Western immunoblotting}

For protein analysis from $\mathrm{C} 2 \mathrm{C} 12$ cells, media was aspirated at the conclusion of treatment and attached cells were lysed directly in the plate on ice in cold RIPA buffer $(50 \mathrm{mM}$ Tris-HCl, $150 \mathrm{mM} \mathrm{NaCl}, 1 \mathrm{mM}$ EDTA, 1 \% Triton X-100, $1 \%$ Na-Deoxycholate, $0.1 \%$ SDS, protease inhibitor cocktail) for $10 \mathrm{~min}$. Lysates were collected into Eppendorf tubes and diluted in $4 \times$ Lammeli sample buffer $(0.25 \mathrm{M}$ Tris- $\mathrm{HCl}$, pH6.8, 6 \% SDS, 40 \% glycerol, $0.04 \%$ bromophenol blue, $16 \%$ DTT), run on 4-15\% Criterion TGX Stain-Free gels (Bio-Rad Laboratories, Gladesville, NSW, Australia) at a constant voltage of $100 \mathrm{~V}$ and transferred to PVDF membranes by wet transfer. 
For protein analysis from muscle tissues, the remaining OCT embedded right TA muscle was excised from the OCT media with a razor blade following sectioning. Excised muscles were homogenized in metal bead-containing matrix tubes in cold RIPA buffer $(50 \mathrm{mM}$ Tris- $\mathrm{HCl}$, $150 \mathrm{mM} \mathrm{NaCl}, 1 \mathrm{mM}$ EDTA, $1 \%$ Triton X-100, $1 \%$ Na-Deoxycholate, $0.1 \%$ SDS, protease inhibitor cocktail) using a Precellys24 automated homogenizer. Homogenized muscle samples were diluted in $3 \times$ SDS loading buffer (125 mM Tris- $\mathrm{HCl}, 4 \mathrm{M}$ urea, 10 \% glycerol, 4 \% SDS, $10 \%$ $\beta$-ME, and $0.001 \%$ bromophenol blue) according to muscle wet concentration and run on 4-15\% Criterion TGX Stain-Free gels (Bio-Rad Laboratories) at a constant voltage of $200 \mathrm{~V}$ and transferred to PVDF membranes using the Trans-Blot Turbo system (Bio-Rad Laboratories).

Membranes were blocked in $5 \%$ BSA in TBST and incubated at $4{ }^{\circ} \mathrm{C}$ overnight in primary antibody solutions. Horseradish peroxidase (HRP)-conjugated secondary antibodies were applied for $1 \mathrm{~h}$ at RT. Membranes were visualized with ECL (SuperSignal West Femto Chemiluminescent Substrate, Thermo Scientific Pierce, IL, USA) and imaged using ChemiDoc MP Imaging System. A stain-free image of each gel was acquired prior to transfer. ECL and stain-free images were quantified using Image Lab 4.1 software (Bio-Rad Laboratories). The intensity of each protein of interest was normalized to the total protein content of the sample as determined from the stain-free image as described previously [33].

\section{Statistical analyses}

For in vitro studies, data were analyzed between groups using a one-way analysis of variance (ANOVA) with a Fisher's LSD post hoc multiple comparisons test for comparison to untreated cells. For all in vivo work, data were analyzed between groups for the effect of genotype and time using a two-way ANOVA with Fisher's LSD post hoc multiple comparisons test used to detect significant differences between means where appropriate. A $P$ value less than 0.05 was considered statistically significant. All statistical analyses were carried out using Prism Graphpad 6 software (GraphPad Software Inc., La Jolla, CA, USA). All values are presented as mean \pm standard error of mean (SEM).

\section{Results}

Inflammatory cytokines induce JAK/STAT signaling and SOCS3 protein in myoblasts and myotubes in vitro

The pro-inflammatory cytokines IL- 6 , IFN- $\gamma$, and TNF- $\alpha$ induce JAK/STAT signaling and are expressed at high levels after myotoxic injury [34-36]. The signaling pathways induced by these cytokines specifically within muscle cells were examined in $\mathrm{C} 2 \mathrm{C} 12$ myoblasts and myotubes in vitro. While no STAT3 phosphorylation was observed in unstimulated $\mathrm{C} 2 \mathrm{C} 12$ myoblasts $(0 \mathrm{~h})$, a low basal level of phosphorylated STAT3 was present in unstimulated $\mathrm{C} 2 \mathrm{C} 12$ myotubes (0 h; Fig. 1a). Addition of rm IL-6 (100 ng/mL) significantly increased STAT3 phosphorylation after 15 min stimulation in both myoblasts and myotubes which decreased at $1 \mathrm{~h}$ stimulation (Fig. 1a). In comparison, stimulation with $\mathrm{rm}$ IFN- $\gamma$ (100 ng/mL) induced very low levels of STAT3 phosphorylation in both myoblasts and myotubes, and rm TNF- $\alpha$ stimulation (10 ng/mL) did not induce phosphorylation of STAT3 in either cell population (Fig. 1a). Phosphorylation of STAT1 occurred within $15 \mathrm{~min}$ and up to $4 \mathrm{~h}$ of stimulation with rm IFN- $\gamma$ in $\mathrm{C} 2 \mathrm{C} 12$ myoblasts and to a lesser extent in $\mathrm{C} 2 \mathrm{C} 12$ myotubes (Fig. 1b). No significant STAT1 phosphorylation was observed following rm IL-6 or rm TNF- $\alpha$ stimulation in either cell type (Fig. 1b).

STAT3 dimerizes after phosphorylation and translocates to the nucleus where it regulates the transcription of many genes, including SOCS3, which in turn negatively regulates the activation of STAT3 [37]. SOCS3 protein was increased after $30 \mathrm{~min}$ and $1 \mathrm{~h}$ of rm IL-6 stimulation, but not $\mathrm{rm}$ IFN- $\gamma$ or $\mathrm{rm}$ TNF- $\alpha$ stimulation, in myoblasts or myotubes (Fig. 1c). Together, these data demonstrate that inflammatory cytokines, particularly IL-6, activate signaling pathways directly within skeletal muscle cells, resulting in production of SOCS3 protein.

SOCS3 deletion specifically within mature muscle fibers does not alter the regenerative response after myotoxic injury

As our in vitro data demonstrated that JAK/STAT signaling induced SOCS3 protein expression in both skeletal muscle myoblasts and mature myotubes, we utilized the SOCS3 ${ }^{\mathrm{fl} / \mathrm{fl}}$ MCK-Cre mouse, in which the Socs3 gene is deleted only in cells expressing muscle creatine kinase (MCK), to determine whether absence of SOCS3 in mature skeletal muscle fibers impairs muscle fiber regeneration. The specificity of the MCK-Cre mediated SOCS3 deletion was confirmed by genomic PCR which showed the presence of the $288 \mathrm{bp}$ deleted SOCS3 fragment in skeletal muscles but not livers of SOCS3 MKO mice (Additional file 1: Figure S1A, B) and by qPCR which demonstrated a lipopolysaccharide (LPS)-induced increase in Socs 3 gene expression in isolated fibers from freeze-dried gastrocnemius muscles from control but not SOCS3 MKO mice (Additional file 1: Figure S1C).

To determine the time-points after myotoxic injury in which SOCS3 deletion would be expected, we examined the gene expression of MCK. In both control and SOCS3 MKO mice, $M C K$ gene expression was detected in uninjured muscle (UN), decreased at day 1 , day 2 , and day 3 and subsequently increased progressively from day 5 to day 14 post-notexin injury (Fig. 2a; $P<0.0001$ injury main effect). However, $M C K$ expression was lower in uninjured muscles from SOCS3 $\mathrm{MKO}$ mice relative to 


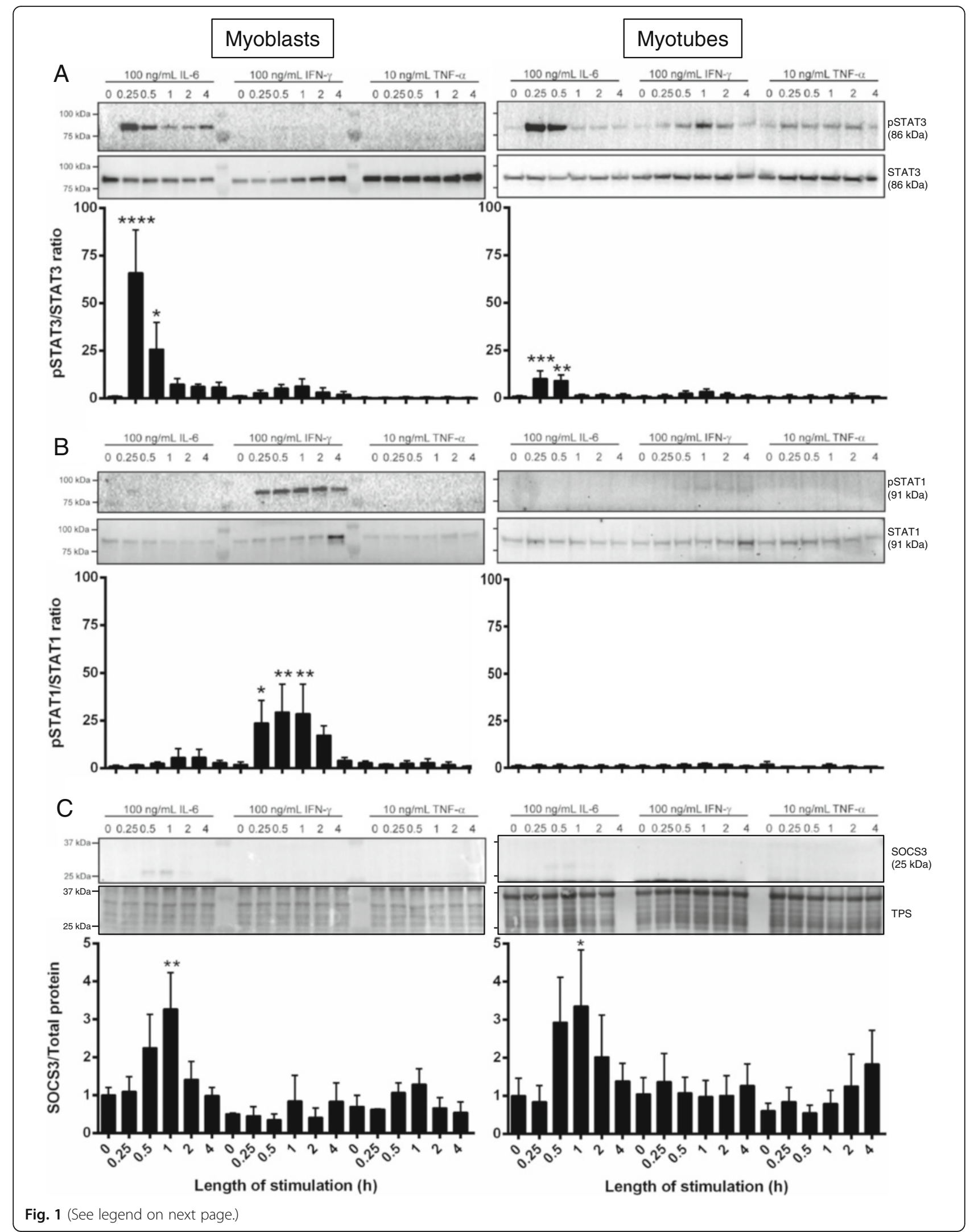


(See figure on previous page.)

Fig. $1 \mathrm{lL}-6$ and IFN- $\gamma$ stimulation initiate JAK/STAT signaling in C2C12 myoblasts and myotubes in vitro. C2C12 proliferating myoblasts (left) or differentiated day 5 myotubes (right) either remained unstimulated (0) or were incubated with $100 \mathrm{ng} / \mathrm{mL} \mathrm{rmlL}-6,100 \mathrm{ng} / \mathrm{mL} \mathrm{rmlFN}-\gamma$, or $10 \mathrm{ng} /$ $\mathrm{mL}$ rmTNF-a for $0.25,0.5,1,2$, or $4 \mathrm{~h}$ at $37^{\circ} \mathrm{C}+5 \% \mathrm{CO}_{2}$. At the conclusion of stimulation, cells were lyzed and subject to SDS-PAGE and western immunoblotting for either pSTAT3/STAT3 (a), PSTAT1/STAT1 (b), or SOCS3 and total protein (TPS; c). Representative immunoblots are shown for each probe with $n=1$ per time-point. Three individual experiments were performed, and bands were quantified to produce the graphs shown. Data are expressed as mean \pm SEM. Statistical analysis was performed using a one-way ANOVA with a Fisher's LSD post hoc multiple comparisons test to determine the effect of treatment. ${ }^{*} P<0.05$, ${ }^{* *} P<0.01$, ${ }^{* *} P<0.001$, ${ }^{* * *} P<0.0001$ compared to unstimulated cells

control (Fig. 2a; ${ }^{* *} P<0.01$ ). Socs3 gene expression was detected at low levels in uninjured muscles and was not different between muscles from control and SOCS3 MKO mice (Fig. 2b). In control mice, Socs3 gene expression increased at day 1 post-notexin injury and decreased progressively to basal levels by day 14 (Fig. $2 \mathrm{~b}$; $P<0.0001$ injury main effect). The increase in Socs3 gene expression after notexin injury was delayed in muscles from SOCS3 MKO mice, being lower at day $1\left({ }^{* *} P<0.01\right)$ and higher at day $2(* P<0.05)$ compared to control but decreased to basal levels by day 14 (Fig. 2b; $P<0.0001$ injury main effect). Therefore, deletion of Socs3 in MCKexpressing mature muscle fibers alters the expression profile of the Socs3 gene after myotoxic injury.

To examine the progression of muscle regeneration post-injury, we analyzed the gene expression of the muscle stem cell marker, Pax7 (Fig. 2c), the master myogenic regulator, $M y o D$ (Fig. 2d), and the marker of early muscle cell differentiation, Myogenin (Fig. 2e). In muscles from both control and SOCS3 MKO mice, the expression of all three markers was low in uninjured muscles and at day 1 and day 2 post-notexin injury,
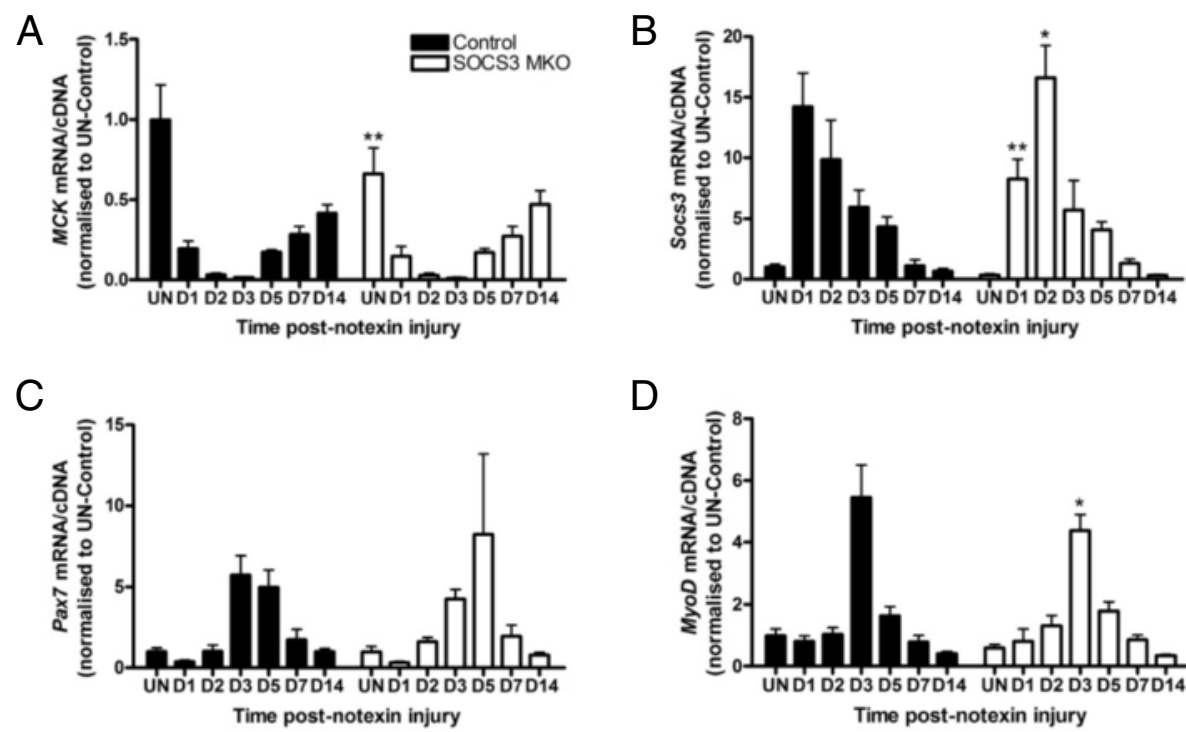

D
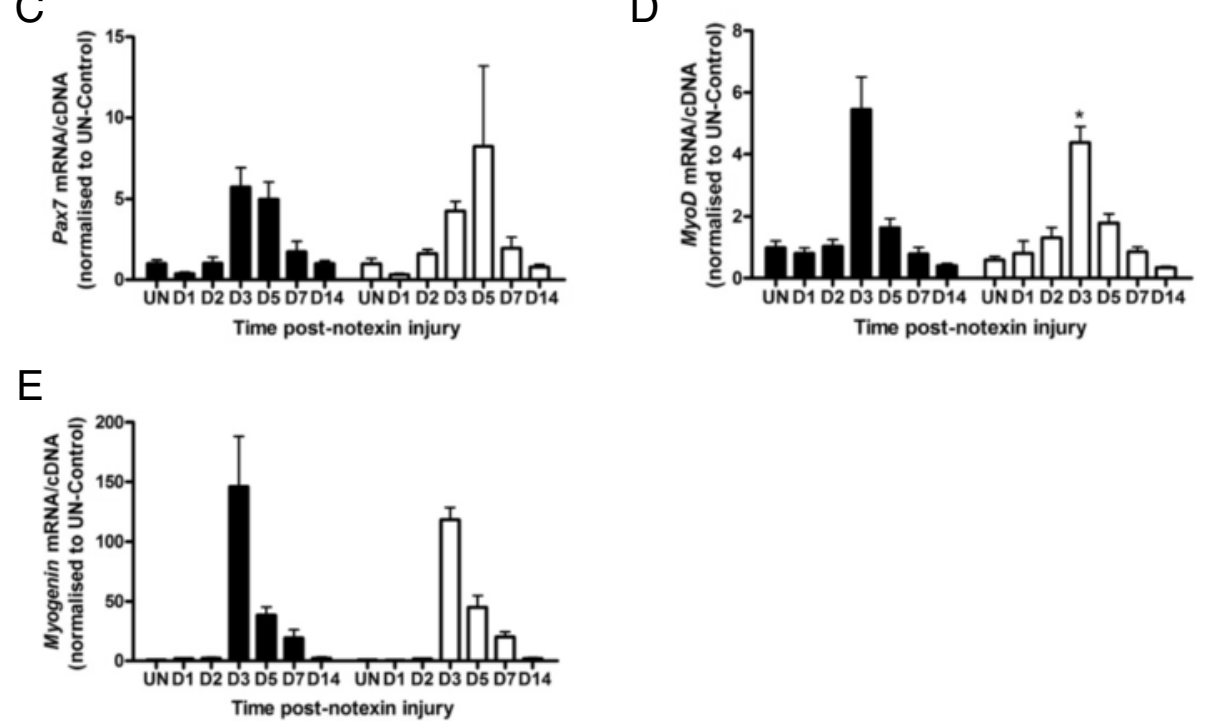

Fig. 2 SOCS3 deletion in mature myofibers in vivo does not alter regeneration after myotoxic injury. Control (SOCS3 ${ }^{\text {fl/fl }}$ MCK-Cre $)$ and SOCS3 MKO (SOCS3 $\left.{ }^{\mathrm{fl} / \mathrm{fl}} \mathrm{MCK}-\mathrm{Cre}^{+}\right)$mice were either left uninjured (UN) or received a single $40 \mu \mathrm{L}$ injection of notexin $(10 \mu \mathrm{g} / \mathrm{ml})$ into the right TA muscle and were killed for analysis at 1 day (D1), 2 days (D2), 3 days (D3), 5 days (D5), 7 days (D7), or 14 days (D14) post-notexin injury. qRT-PCR using primers to detect MCK (a), Socs3 (b), Pax7 (c), MyoD (d), and Myogenin (e) was performed on RNA extracted from snap frozen muscles following dissection. Data are expressed as mean \pm SEM. Statistical analysis was performed using a two-way ANOVA with a Fisher's LSD post hoc multiple comparisons test to determine the effects of genotype and time. $n=8$ mice/time-point/genotype. ${ }^{*} P<0.05$, ${ }^{* *} P<0.01$ compared to control 
peaked at day 3 , and subsequently decreased to basal levels by day 14 (Fig. 2c-e; $P<0.001$ injury main effect). While $M y o D$ expression was decreased slightly at day 3 post-notexin injury in muscles from SOCS3 MKO mice relative to control (Fig. $2 \mathrm{~d} ;{ }^{*} P<0.05$ ), the time-course of Pax7, MyoD, and Myogenin gene expression did not vary compared with control indicating that regeneration was not altered by muscle fiber-specific SOCS3 deletion.

Loss of SOCS3 in skeletal muscle fibers increases the early inflammatory response after myotoxic injury

We examined the effect of SOCS3 deletion on the activation of JAK/STAT signaling during regeneration after myotoxic injury. No phosphorylation of JAK1, JAK2, STAT1, or STAT5 was detected in muscle lysates from uninjured control or SOCS3 MKO mice (data not shown). In control and SOCS3 MKO mice, STAT3 phosphorylation was not detected in uninjured muscles but was increased at day 1 post-notexin injury and remained constant at days 2, 3, and 5 then decreased to basal levels by day 7 (Fig. 3a; $P<0.0001$ injury main effect). In muscles from SOCS3 MKO mice, STAT3 phosphorylation was significantly increased compared to muscles from control mice at day 1 post-notexin injury (Fig. 3a; **P $P<0.01$ compared to control).

As increased STAT3 phosphorylation is an indicator of an increased inflammatory response, we next examined the presence of inflammatory cells and the gene expression of inflammatory markers. Immunostaining for the inflammatory cell markers F4/80 (Fig. 3b) and CD68 (Fig. 3c) showed increased presence of these cells at D2 and D3 following injury in muscles from control and SOCS3 MKO mice and indicated an increased infiltration of inflammatory cells at D2 following injury in muscles from SOCS3 MKO mice compared to control (Fig. 3b, c). The inflammatory cytokine $I L-6$ gene was expressed at low levels in uninjured muscles, highly expressed at day 1 and day 2 post-injury and decreased to basal levels by day 14 (Fig. $3 d ; P<0.0001$ injury main effect). Gene expression of IFN- $\gamma$ increased around day 3 post-notexin injury and was barely detected by day 14 (Fig. 3e; $P<0.01$ injury main effect). SOCS3 deletion had no effect on $I L-6$ (Fig. 3d) or IFN- $\gamma$ (Fig. 3e) expression after myotoxic injury.

The gene expression of the pro-inflammatory cytokine $T N F-\alpha$, as well as the inflammatory cell markers $F 4 / 80$ and $C D 68$, was low in uninjured muscles from control and SOCS3 MKO mice, increased progressively to day 3, then reduced to basal levels by day 14 post-notexin injury (Fig. 3f-h; $P<0.0001$ time main effect). In muscles from SOCS3 MKO mice, TNF- $\alpha, F 4 / 80$ and CD68 gene expression was higher compared to muscles from control mice at day 2 post-notexin injury (Fig. 3f-h;
**** $P<0.0001, \quad{ }^{* *} P<0.01, \quad{ }^{* * *} P<0.001, \quad$ respectively). Together, these results suggest that muscle fiber-specific SOCS3 deletion increases the inflammatory signal at day 1 , resulting in an enhanced inflammatory response at day 2 , which appears resolved by day 3 post-notexin injury.

\section{Skeletal muscle fiber-specific deletion of SOCS3 does not alter force production before or after myotoxic injury}

To determine whether an enhanced early inflammatory response after myotoxic injury in muscles lacking SOCS3 had any effect on muscle function, we next examined mass and force production of uninjured and notexin-injured TA muscles from control and SOCS3 $\mathrm{MKO}$ mice. Histology of uninjured muscles from aged control and SOCS3 MKO mice appeared normal and ongoing repair was observed in injured muscles as indicated by the continued presence of centrally-nucleated fibers, which looked similar in SOCS3 MKO muscles (Fig. 4a, b). Skeletal muscle-specific deletion of SOCS3 did not affect the mass of the uninjured right TA muscle or at 7 days post-notexin injury, but control and SOCS3 $\mathrm{MKO}$ muscles were smaller after notexin injury (Fig. 4c; $P<0.01$ injury main effect). Similarly, average muscle fiber cross-sectional area (CSA) was reduced at 7 days post-injury compared with uninjured muscles and was not changed with SOCS3 deletion (Fig. $4 \mathrm{~d}$; $P<0.0001$ injury main effect). Both maximum isometric force and specific force were reduced 7 days after notexin injury compared with uninjured muscles and were similarly not affected by SOCS3 deletion (Fig. 4e, f; $P<0.0001$ injury main effect). SOCS3 deletion did not affect force production at any stimulation frequency in either the uninjured muscles (Additional file 2: Figure S2A) or in muscles at 7 days post-injury (Additional file 2: Figure $\mathrm{S} 2 \mathrm{~B})$. Notexin injury reduced force production during a 4-min fatiguing protocol in control mice (Fig. 4g; $P<0.05$ compared with uninjured muscles), but there was no difference in the fatigue response between uninjured and injured muscles of SOCS3 MKO mice (Fig. 4h). Analysis of force production over the 4-min fatiguing protocol between uninjured muscles from control and SOCS3 $\mathrm{MKO}$ mice showed this difference to be due to an increased fatigue response in the uninjured muscles of SOCS3 MKO mice (Fig. 4i; ${ }^{*} P<0.05$ compared to control). Gene expression analysis showed no significant change in expression of myosin heavy chain isoforms $M y H C I I b$ (Additional file 3: Figure S3A), MyHCIIx (Additional file 3: Figure S3B), $M y H C I$ (Additional file 3: Figure S3C), or MyHCIIa in muscles from SOCS3 MKO mice (Additional file 3: Figure S3D), and oxidative capacity of muscles from SOCS3 MKO was unchanged compared to control (Additional file 3: Figure S3E). 


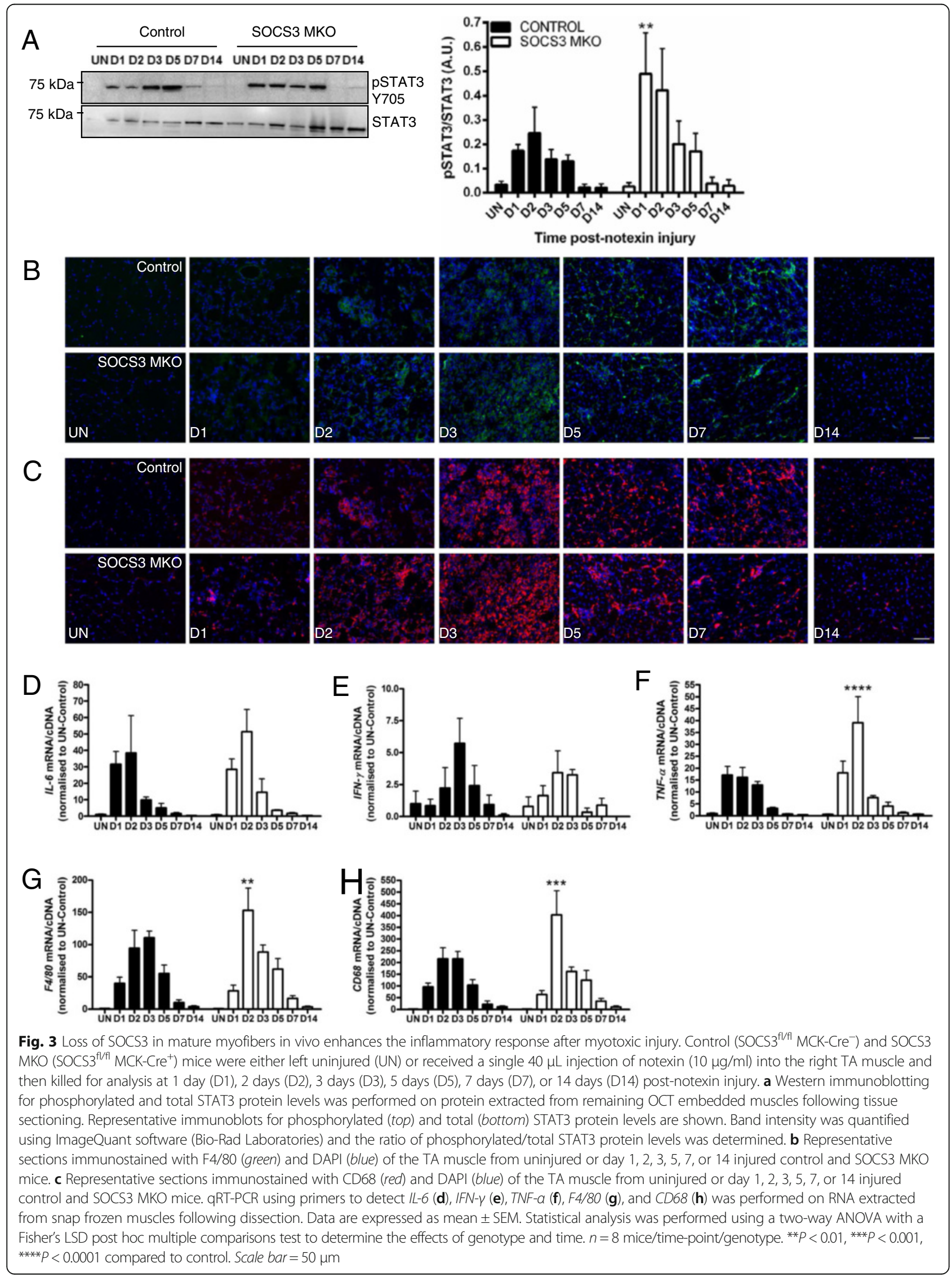



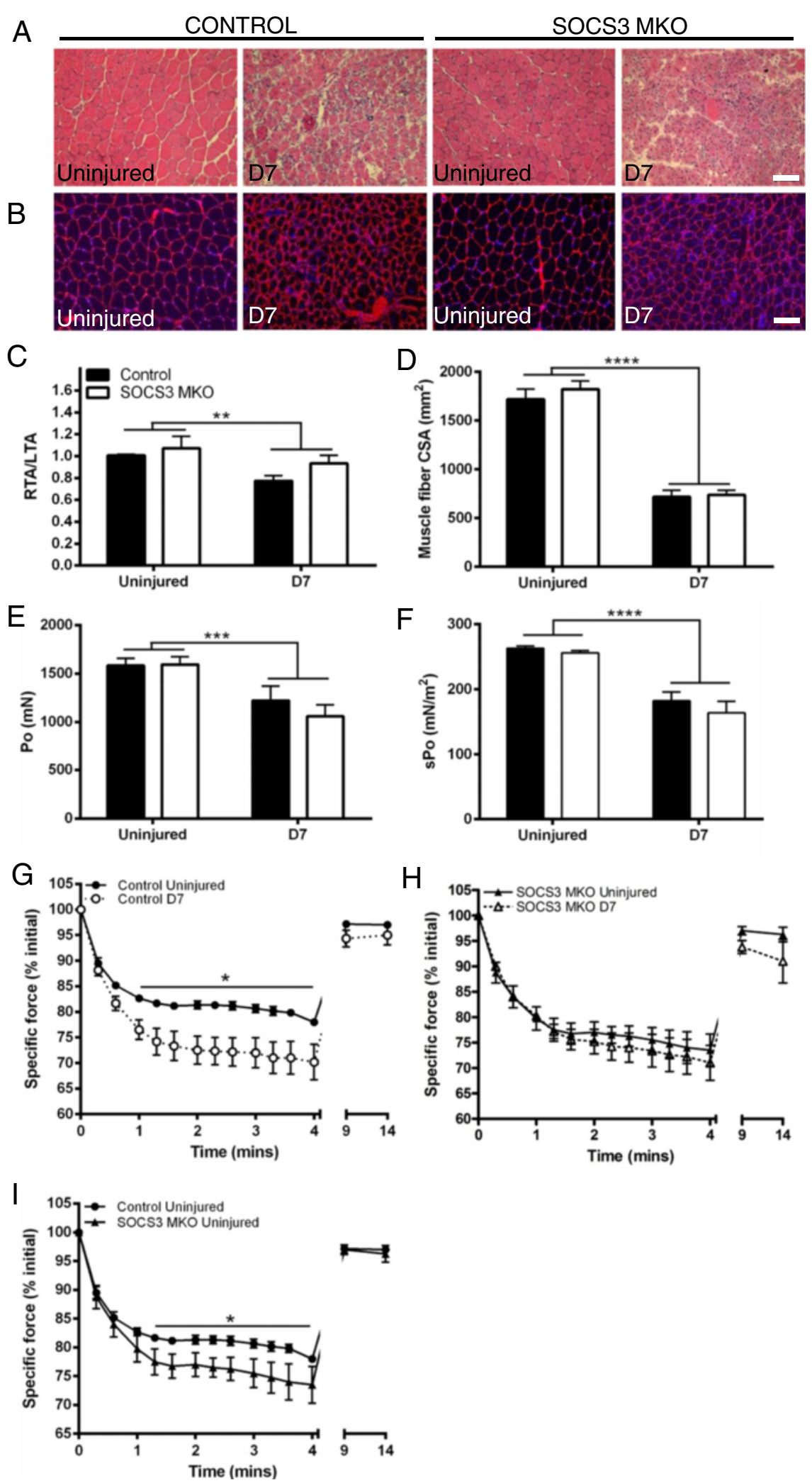

Fig. 4 (See legend on next page.) 
(See figure on previous page.)

Fig. 4 Skeletal muscle fiber-specific deletion of SOCS3 does not alter force production of the TA muscles. Control (SOCS3 ${ }^{\mathrm{fl} / f l}$ MCK-Cre ${ }^{-}$) and SOCS3 MKO (SOCS3 ${ }^{\text {fl/fl }}$ MCK-Cre ${ }^{+}$) mice were either left uninjured (UN) or received a single $40 \mu \mathrm{L}$ injection of notexin $(10 \mu \mathrm{g} / \mathrm{ml})$ into the right TA muscle. Representative hematoxylin and eosin (a) and laminin and DAPI (b) stained sections of TA muscle from uninjured or day 7 injured control and SOCS3 MKO mice. Muscle mass relative to the uninjured left TA muscle (c), muscle fiber size (d), maximum isometric force (e), and specific (normalized) force (f) were determined at day 7 post-notexin injury. Data are expressed as mean \pm SEM. Statistical analysis was performed using a two-way ANOVA with a Fisher's LSD post hoc multiple comparisons test to determine effects of genotype and time. $n=8$ mice/ time-point/genotype. ${ }^{* *} P<0.01,{ }^{* *} P<0.001,{ }^{* * *} P<0.0001$ compared to uninjured muscle. Specific force production during a 4 -min fatiguing protocol comparing uninjured and day 7 injured right TA muscles from control mice (g), SOCS3 MKO mice (h), and comparing uninjured control and SOCS3 MKO mice separately (i). Data are expressed as mean \pm SEM. Statistical analysis was performed using a repeated measures two-way ANOVA with a Fisher's LSD post hoc multiple comparisons test to determine effects of genotype and time. $n$ $=8 \mathrm{mice} /$ time-point/genotype. ${ }^{*} P<0.05$ compared to uninjured muscle from control mice. Scale bar $=50 \mu \mathrm{m}$

\section{Loss of SOCS3 does not alter regeneration or} inflammation after myotoxic injury in aged mice

As skeletal muscle-specific SOCS3 deletion models reduced SOCS3 levels and lower SOCS3 levels have been reported in muscles from aged mice [29], we next examined whether loss of SOCS3 in skeletal muscles impacted on muscle regeneration in aged ( 24 month old) mice. Notexin injuries were performed on 24-month-old control and SOCS3 $\mathrm{MKO}$ mice ( $n=7-8 /$ genotype) and markers of regeneration and inflammation were assessed in the injured muscles at 7 days post-injury. Histology of uninjured muscles from aged control and SOCS3 MKO mice appeared normal, but consistent with previous reports, ongoing inflammation and repair was observed in injured 24-month-old control muscles, which looked similar in SOCS3 MKO muscles (Fig. 5a). At 7 days post-notexin injury, SOCS3 deletion did not alter TA mass relative to body mass (Fig. 5b), and while muscle fiber CSA was significantly smaller in injured muscles, SOCS3 deletion had no further effect (Fig. 5c; ****: $P<0.0001$ injury main effect).

Western immunoblotting revealed no difference in STAT3 phosphorylation in SOCS3 MKO muscles compared to control (Fig. 5d), and no change was observed in Socs3 RNA levels between control and SOCS3 MKO mice at 7 days post-notexin injury, likely due to the continued expression of Socs3 by muscle resident cells other than the myofibers (Fig. 5e). While no significant changes were observed, gene expression levels of the inflammatory cytokines $I L-6$ (Fig. 5f; $P=0.05$ ) and TNF- $\alpha$ (Fig. 5g; $P=0.1$ ) but not $I F N-\gamma$ (Fig. $5 \mathrm{~h} ; P=0.84$ ) or the inflammatory cell markers $F 4 / 80$ (Fig. $5 \mathrm{i} ; P=0.19$ ) or CD68 (Fig. 5j; $P=0.16$ ) tended to be increased in muscles from SOCS3 MKO mice compared to control at 7 days post-notexin injury. Similarly, gene expression levels of the myogenic markers $\operatorname{Pax} 7$ (Fig. 5k; $P=0.15$ ), $M y o D$ (Fig. 5l; $P=0.28$ ), and Myogenin (Fig. $5 \mathrm{~m} ; P=0.21$ ) were not changed in muscles of SOCS3 MKO mice compared with control at 7 days post-injury.

\section{Discussion}

SOCS3 RNA and/or protein levels are altered in muscles with aging [27-29] and may be implicated in impaired muscle regeneration with aging; but whether they increase or decrease remains to be determined. SOCS3 is expressed by multiple cell types in regenerating skeletal muscles, but the relative contribution of SOCS3 within each cell type to altered muscle inflammation and regeneration is unknown. Using mice specifically lacking SOCS3 in MCK-expressing mature muscle fibers, we have shown that although reduced SOCS3 expression increases the early inflammatory response in skeletal muscle after myotoxic injury, this does not impact regeneration.

SOCS3 MKO mice undergo normal muscle development and exhibit improved insulin sensitivity when fed a high fat diet compared to control mice [26]. Consistent with these findings, we observed no significant changes in muscle structure and function between injured and uninjured muscles of control and SOCS3 MKO mice. However, uninjured TA muscles from SOCS3 MKO mice were more susceptible to fatigue than muscles from control mice, in the absence of any changes in oxidative capacity or $\mathrm{MyHC}$ isoform gene expression. Treadmill running performance was unchanged between control and SOCS3 MKO mice [26], indicating that while muscle fiber-specific SOCS3 deletion increased fatigue in contracting TA muscles, overall exercise capacity was unaffected.

JAK/STAT signaling is intact in C2C12 cells in vitro, with addition of leukemia inhibitory factor (LIF), basic fibroblast growth factor (bFGF), growth hormone (GH), and leptin or insulin-like growth factor (IGF) all activating STAT3 [38-41]. The time-course of activation of STAT3 and induction of SOCS3 following addition of IL-6 to $\mathrm{C} 2 \mathrm{C} 12$ cells was consistent with previous observations of the IL- 6 family cytokine, LIF, in mouse embryonic stem (ES) cells, and the related cytokine granulocyte colony stimulating factor (G-CSF) in isolated mouse bone marrow cells [14, 42], indicating that muscle cells employ similar JAK/STAT signaling mechanisms to these other cell types. TNF- $\alpha$ and IFN- $\gamma$ directly upregulate SOCS3 expression in hematopoietic cells and liver [37, 43-45], but we were unable to detect SOCS3 expression in $\mathrm{C} 2 \mathrm{C} 12$ cells following stimulation 
A

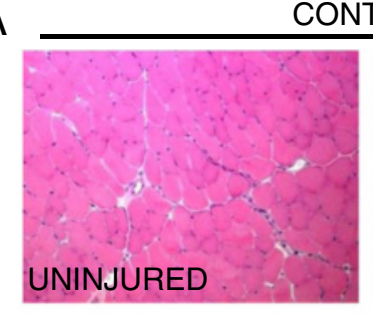

CONTROL

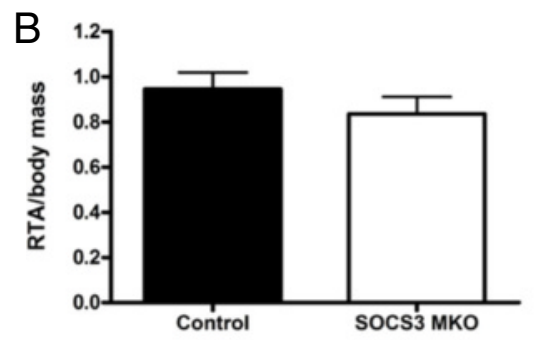

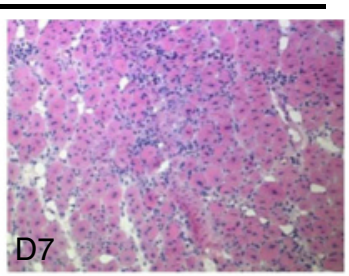

C

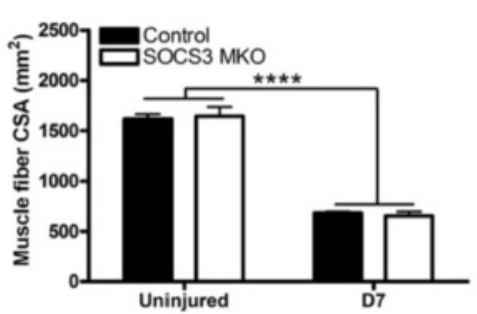

D

D7 post-notexin injury

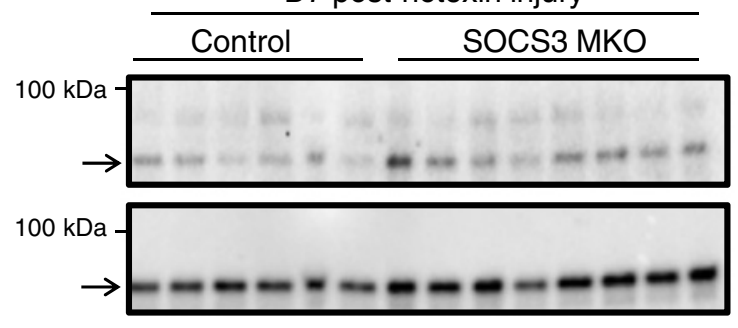

STAT3

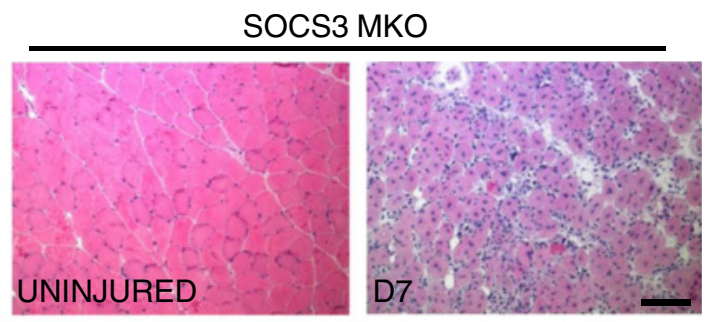

E

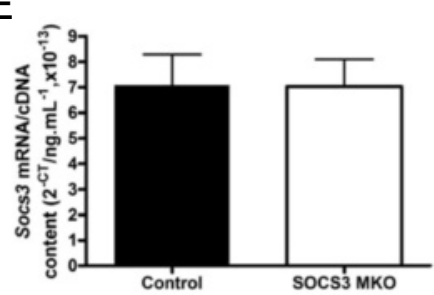

$\mathrm{H}$

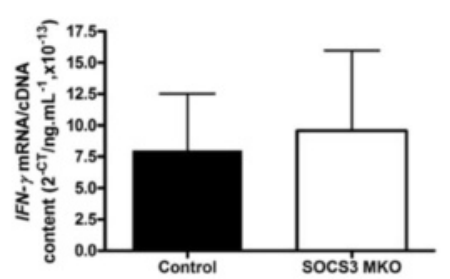

$\mathrm{K}$

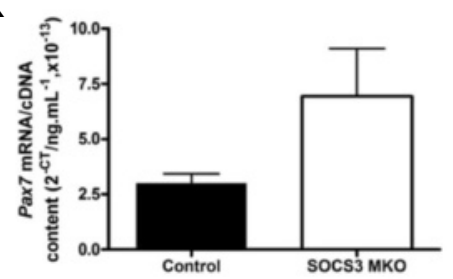

$\mathrm{F}$

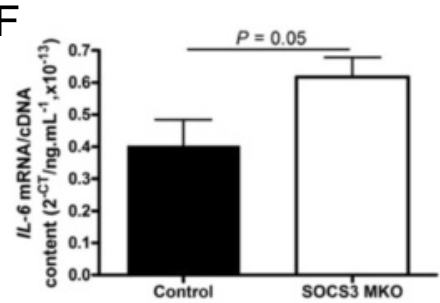

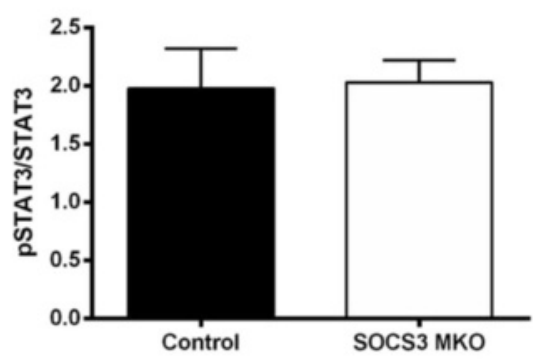

$\mathrm{G}$

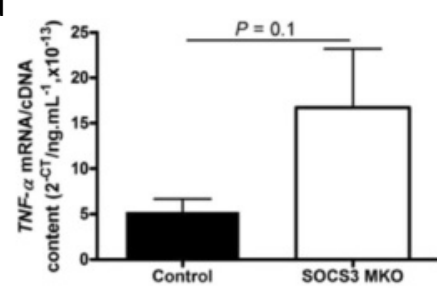

J
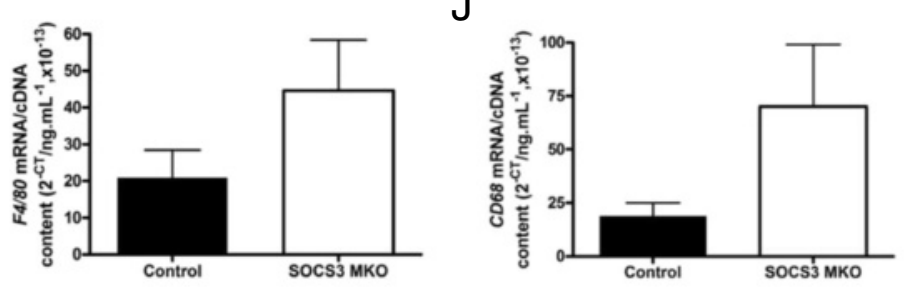

$\mathrm{L}$

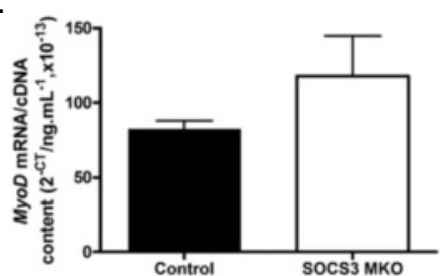

M

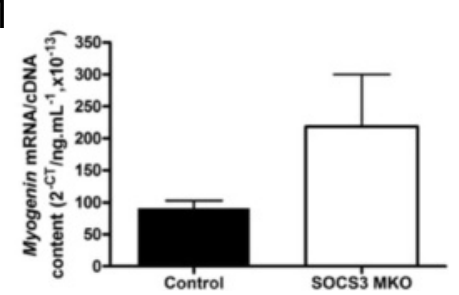

Fig. 5 (See legend on next page.) 
(See figure on previous page.)

Fig. 5 SOCS3 deletion does not alter regeneration or inflammation after myotoxic injury in aged mice. Twenty-four-month-old control (SOCS3 $3^{\mathrm{fl} / \mathrm{fl}}$ MCK-Cre $)$ and SOCS3 MKO (SOCS ${ }^{f / f l}$ MCK-Cre $)$ mice were either left uninjured (UN) or received a single $40 \mu \mathrm{L}$ injection of notexin (10 $\left.\mu \mathrm{g} / \mathrm{ml}\right)$ into the right TA muscle. a Representative hematoxylin and eosin-stained sections of the TA muscle from uninjured or day 7 injured control and SOCS3 MKO mice. Muscle mass relative to body mass (b) and muscle fiber size (c) was determined at day 7 post-notexin injury. $\mathbf{d}$ Western immunoblotting for phosphorylated and total STAT3 protein levels was performed on protein extracted from the remaining OCT embedded muscles following tissue sectioning. Representative immunoblots for phosphorylated (top) and total (bottom) STAT3 protein levels are shown. Band intensity was quantified using ImageQuant software (Bio-Rad Laboratories), and the ratio of phosphorylated/total STAT3 protein levels was determined. Bands used for quantification are indicated by arrows. qRT-PCR using primers to detect Socs3 (e), IL-6 (f), TNF- $a(\mathbf{g})$, IFN- $\gamma$ (h), F4/80 (i), CD68 (j), Pax7 (k), MyoD (I), or Myogenin ( $\mathbf{m})$ was performed on RNA extracted from snap frozen muscles following dissection. Data are expressed as mean \pm SEM. Statistical analysis was performed using an unpaired two-tailed Student's $t$ test ( $n=7-8$ mice/time-point/genotype) except for analysis of muscle fiber size (c) which was analyzed with a two-way ANOVA and Fisher's LSD post hoc multiple comparisons test to determine the effect of genotype and injury ( $n=4-8$ mice/time-point/genotype). Scale bar $=100 \mu \mathrm{m}$

with either IFN- $\gamma$ or TNF- $\alpha$. Endogenous SOCS3 protein expression is generally quite low and difficult to detect [46]. Therefore, if addition of TNF- $\alpha$ or IFN- $\gamma$ did increase SOCS3 protein expression in $\mathrm{C} 2 \mathrm{C} 12$ cells, this was below the level of detection and not to the level induced by IL-6 stimulation.

SOCS3 is a critical regulator of inflammatory signaling in many cell types. Conditional ablation of SOCS3 in various tissues, including hematopoietic cells and liver causes enhanced inflammation and emergency granulopoiesis $[16,17,47-49]$. Therefore, our observation of an increased inflammatory response after myotoxic damage in SOCS3 MKO mice was not unexpected. Increased inflammation could impact regeneration, but we observed no change in the regenerative capacity of muscles from SOCS3 MKO mice compared with control, likely because of the rapid resolution of the increased inflammatory cell infiltrate by D3 after injury.

SOCS3 is present in mature muscle fibers but also expressed in both muscle stem cells and inflammatory cells which are critical for successful muscle regeneration. We observed Socs3 gene expression at varying levels after myotoxic injury in SOCS3 MKO mice indicating that SOCS3-expressing cells (most likely a combination of these two cell types) were present in the muscle at these times. SOCS3 expression is critical for the proper regulation of inflammatory cell function in multiple states of inflammation [14-17, 47, 48], and regulation of JAK/STAT signaling is critical to skeletal muscle stem cell function. Microarray studies have shown reduced Socs 3 gene expression upon muscle stem cell activation [19]. Furthermore, increased STAT3 activation has been reported in muscle stem cells isolated from muscles of old mice compared with those from younger mice [50] and reduction of STAT3 activation by either conditional ablation or transient pharmacologic inhibition modulates the proliferative and differentiation potential of the muscle stem cell pool $[50,51]$. Therefore, SOCS3 expression and function is likely critical in the regulation of both the inflammatory response and muscle stem cell function in the context of muscle injury. We had hypothesized that reduced SOCS3 expression or function contributed to age-related impairments in muscle regeneration, but since regeneration was not impaired in SOCS3 MKO mice, reduced SOCS3 expression or function within the mature muscle fiber is unlikely to contribute directly. It remains possible that reduced SOCS3 protein expression within the muscle stem cell pool and/or inflammatory cells might impair the injury-repair process.

\section{Conclusions}

Specific deletion of SOCS3 within MCK-expressing muscle fibers, which models the reduced SOCS3 expression thought to occur in muscles with aging, enhanced the early inflammatory response but ultimately did not affect muscle regeneration after myotoxic injury. Furthermore, inflammation and muscle regeneration were not altered after myotoxic injury in the muscles of 24-month-old SOCS3 MKO mice compared with control. Therefore, reduced SOCS3 expression/function within the muscle fiber is likely not a contributing factor to age-related impairments in muscle regeneration. However, since SOCS3 is expressed in other muscle resident cells, including hematopoietic cells and muscle stem cells, it remains possible that the expression level and/or function of SOCS3 may be altered in these populations with age. Further studies examining the effect of SOCS3 deletion in these populations on muscle regeneration are warranted.

\section{Additional files}

Additional file 1: Figure S1. Genomic PCR to confirm correct Socs3 deletion. (A) Schematic of Socs3 gene demonstrating floxed regions (LoxP) flanking exon 2 and location of the sequencing primers both prior to and post-Cre excision. (B) Genomic PCR using the primers shown in (A) confirmed the presence of the $288 \mathrm{bp}$ deleted DNA band in muscle but not liver of SOCS3 ${ }^{f / f l}$ MCK-Cre positive and not SOCS3 ${ }^{\mathrm{fl} / \mathrm{ll}}$ MCK-Cre-negative mice. (C) qRT-PCR using primers to detect Socs3 gene expression in RNA extracted from muscle fibers isolated from freeze-dried gastrocnemius muscles of saline or LPS-injected control and SOCS3 MKO mice. Data are expressed as mean \pm SEM and compared with a two-way ANOVA and Fisher's LSD post hoc multiple comparisons test to determine the effect of genotype and LPS 
injection ( $n=2$ mice/genotype). ${ }^{* *} P<0.001$ compared to uninjured muscle from control mice. (PDF $115 \mathrm{~kb}$ )

Additional file 2: Figure S2. Frequency-force relationships for uninjured and day 7 (D7) notexin-injured muscles from control and SOCS3 MKO mice. Frequency-force relations for specific (normalized) force at different stimulation frequencies $(10-200 \mathrm{~Hz})$ in muscles of either uninjured (A) or day 7 postnotexin-injured (B) control or SOCS3 MKO mice. Data are expressed as mean $\pm \mathrm{SEM}$. Comparisons were made using a two-way repeated measures ANOVA with Fisher's LSD multiple comparisons test post hoc to determine the effect of genotype and stimulation frequency. $n=8$ mice/ genotype. (PDF $99 \mathrm{~kb}$ )

Additional file 3: Figure S3. Myosin heavy chain gene expression and muscle fiber oxidative capacity in muscles from uninjured control and SOCS3 MKO mice. qRT-PCR using primers to detect MyHCllb (A), MyHCIIx (B), $\mathrm{MyHCl}(\mathrm{C})$, and $\mathrm{MyHClla}$ (D) was performed on RNA extracted from snap frozen muscles following dissection. Data are expressed as mean \pm SEM and compared with an unpaired two-tailed Student's $t$ test. $n=8$ mice/genotype. (E) Representative succinate dehydrogenase (SDH)-reacted TA muscle sections from uninjured muscles of 12-week-old control and SOCS3 MKO mice. Quantification of SDH intensity was determined by analysis of SDH reacted TA muscle sections. Data are expressed as mean \pm SEM and compared with an unpaired two-tailed Student's $t$ test. $n=5$ mice/ genotype. Scale bar $=100 \mu \mathrm{m}$. (PDF $145 \mathrm{~kb}$ )

\section{Abbreviations}

AMPK: Adenosine mono-phosphate (AMP)-regulated protein kinase ANOVA: Analysis of variance; bFGF: Basic fibroblast growth factor; CIS: Cytokine-induced STAT inhibitor; CSA: Cross-sectional area; ES: Embryonic stem cell; G-CSF: Granulocyte colony stimulating factor; GH: Growth hormone; HRP: Horseradish peroxidase; Hz: Hertz; IFN- $\gamma$ : Interferon- $\gamma$; IGF: Insulin-like growth factor; IL-6: Interleukin-6; JAK: Janus kinase; LPS: Lipopolysaccharide; MCK: Muscle creatine kinase; MKO: Muscle-specific knockout; MLC: Myosin light chain; MyHC: Myosin heavy chain; OCT: Optimal cutting temperature; PCR: Polymerase chain reaction; SDH: Succinate dehydrogenase; SEM: Standard error of the mean; SOCS: Suppressor of cytokine signaling; STAT: Signal transducers and activators of transcription; TA: Tibialis anterior; TNF-a: Tumor necrosis factor-a; UN: Uninjured

\section{Acknowledgements}

The authors wish to thank Prof. Gregory Steinberg for provision of the sOCS3 ${ }^{\text {fl/fl }}$ MCK-Cre mouse line and Mr. Dale Baum and Dr. Nicola Cranna for assistance with data collection.

\section{Funding}

This work was supported by the Australian Research Council (ARC; DP120101494). KS was supported by an Early Career Fellowship from the National Health and Medical Research Council (NH\&MRC) of Australia.

\section{Availability of data and materials}

The datasets supporting the conclusions of this article are included within the article (and its Additional file 1: Figure S1, Additional file 2: Figure S2, and Additional file 3: Figure S3).

\section{Authors' contributions}

KS and ST designed and carried out the experiments, analyzed the results, and wrote the manuscript. TN, with the support of KS, conducted the animal injury studies and muscle function analyses. AC and JT, with the support of KS, conducted the biochemical and histological analyses. RK and GSL designed the experiments, analyzed the results, wrote the manuscript, and provided the financial support. All authors read and approved the final manuscript.

\section{Authors' information}

AC is currently located at the Department of Biochemistry and Molecular Biology, Monash University, Victoria, Australia.

\section{Competing interests}

The authors declare that they have no competing interests.

\section{Consent for publication}

Not applicable.

\section{Ethics approval}

All experimental protocols were approved by the Animal Ethics Committee of The University of Melbourne and conducted in accordance with the Australian code of practice for the care and use of animals for scientific purposes as stipulated by the National Health and Medical Research Council (Australia).

Received: 19 May 2016 Accepted: 5 October 2016

Published online: 24 October 2016

\section{References}

1. Brack AS, Conboy MJ, Roy S, Lee M, Kuo CJ, Keller C, et al. Increased Wnt signaling during aging alters muscle stem cell fate and increases fibrosis. Science. 2007;317:807-10.

2. Conboy IM, Conboy MJ, Smythe GM, Rando TA. Notch-mediated restoration of regenerative potential to aged muscle. Science. 2003;302:1575-7.

3. Conboy IM, Conboy MJ, Wagers AJ, Girma ER, Weissman IL, Rando TA. Rejuvenation of aged progenitor cells by exposure to a young systemic environment. Nature. 2005:433:760-4.

4. Conboy IM, Rando TA. Aging, stem cells and tissue regeneration: lessons from muscle. Cell Cycle. 2005:4:407-10.

5. Ryall JG, Schertzer JD, Lynch GS. Cellular and molecular mechanisms underlying age-related skeletal muscle wasting and weakness. Biogerontology. 2008;9:213-28.

6. Lu H, Huang D, Ransohoff RM, Zhou L. Acute skeletal muscle injury: CCL2 expression by both monocytes and injured muscle is required for repair. FASEB J. 2011;25:3344-55.

7. Lu H, Huang D, Saederup N, Charo IF, Ransohoff RM, Zhou L. Macrophages recruited via CCR2 produce insulin-like growth factor-1 to repair acute skeletal muscle injury. FASEB J. 2011;25:358-69.

8. Summan M, Warren GL, Mercer RR, Chapman R, Hulderman T, Van Rooijen $\mathrm{N}$, et al. Macrophages and skeletal muscle regeneration: a clodronatecontaining liposome depletion study. Am j physiol Regulatory, integr comparative physiol. 2006;290:R1488-95.

9. Tidball JG. Mechanisms of muscle injury, repair, and regeneration. Comprehensive Physiol. 2011;1:2029-62

10. Tidball JG, Villalta SA. Regulatory interactions between muscle and the immune system during muscle regeneration. Am j physiol Regulatory, integr comparative physiol. 2010;298:R1173-87.

11. Tidball JG, Wehling-Henricks M. Macrophages promote muscle membrane repair and muscle fibre growth and regeneration during modified muscle loading in mice in vivo. J Physiol. 2007;578:327-36.

12. van der Poel C, Gosselin LE, Schertzer JD, Ryall JG, Swiderski K, Wondemaghen $\mathrm{M}$, et al. Ageing prolongs inflammatory marker expression in regenerating rat skeletal muscles after injury. J Inflamm. 2011:8:41.

13. Ivashkiv LB. Crosstalk with the Jak-STAT pathway in inflammation. In: JakStat signaling: from basics to disease. Edited by Decker T, Muller M. Vienna: Springer Science and Business Media; 2012: 353-370.

14. Boyle K, Egan P, Rakar S, Willson TA, Wicks IP, Metcalf D, et al. The SOCS box of suppressor of cytokine signaling-3 contributes to the control of G-CSF responsiveness in vivo. Blood. 2007;110:1466-74.

15. Boyle K, Zhang JG, Nicholson SE, Trounson E, Babon JJ, McManus EJ, et al. Deletion of the SOCS box of suppressor of cytokine signaling 3 (SOCS3) in embryonic stem cells reveals SOCS box-dependent regulation of JAK but not STAT phosphorylation. Cell Signal. 2009;21:394-404.

16. Croker BA, Krebs DL, Zhang JG, Wormald S, Willson TA, Stanley EG, et al. SOCS3 negatively regulates IL-6 signaling in vivo. Nat Immunol. 2003;4:540-5.

17. Croker BA, Metcalf D, Robb L, Wei W, Mifsud S, DiRago L, et al. SOCS3 is a critical physiological negative regulator of G-CSF signaling and emergency granulopoiesis. Immunity. 2004;20:153-65.

18. Jang YN, Baik EJ. JAK-STAT pathway and myogenic differentiation. Jakstat. 2013;2:e23282. doi: 23210.24161/jkst.23282.

19. Fukada S, Uezumi A, Ikemoto M, Masuda S, Segawa M, Tanimura N, et al. Molecular signature of quiescent satellite cells in adult skeletal muscle. Stem Cells. 2007;25:2448-59.

20. McKay BR, Ogborn DI, Baker JM, Toth KG, Tarnopolsky MA, Parise G. Elevated SOCS3 and altered IL-6 signaling is associated with age-related human muscle stem cell dysfunction. Am j physiol Cell physiol. 2013;304:C717-28. 
21. Ryall JG, Dell'Orso S, Derfoul A, Juan A, Zare H, Feng X, et al. The $\mathrm{NAD}(+)$-dependent SIRT1 deacetylase translates a metabolic switch into regulatory epigenetics in skeletal muscle stem cells. Cell Stem Cell. 2015;16:171-83.

22. Spangenburg EE, Brown DA, Johnson MS, Moore RL. Exercise increases SOCS-3 expression in rat skeletal muscle: potential relationship to IL-6 expression. J Physiol. 2006;572:839-48.

23. Yang Z, Hulver M, McMillan RP, Cai L, Kershaw EE, Yu L, et al. Regulation of insulin and leptin signaling by muscle suppressor of cytokine signaling 3 (SOCS3). PLoS One. 2012;7:e47493.

24. Caldow MK, Steinberg GR, Cameron-Smith D. Impact of SOCS3 overexpression on human skeletal muscle development in vitro. Cytokine. 2011;55:104-9.

25. Lebrun P, Cognard E, Bellon-Paul R, Gontard P, Filloux C, Jehl-Pietri C, et al. Constitutive expression of suppressor of cytokine signalling-3 in skeletal muscle leads to reduced mobility and overweight in mice. Diabetologia. 2009;52:2201-12.

26. Jorgensen SB, O'Neill HM, Sylow L, Honeyman J, Hewitt KA, Palanivel R, et al. Deletion of skeletal muscle SOCS3 prevents insulin resistance in obesity. Diabetes. 2013;62:56-64

27. Haddad F, Adams GR. Aging-sensitive cellular and molecular mechanisms associated with skeletal muscle hypertrophy. J Appl Physiol. 2006;100:1188-203.

28. Leger B, Derave W, De Bock K, Hespel P, Russell AP. Human sarcopenia reveals an increase in SOCS-3 and myostatin and a reduced efficiency of Akt phosphorylation. Rejuvenation Res. 2008;11:163-175B.

29. Trenerry MK, Carey KA, Ward AC, Farnfield MM, Cameron-Smith D. Exerciseinduced activation of STAT3 signaling is increased with age. Rejuvenation Res. 2008;11:717-24.

30. Swiderski K, Todorov M, Gehrig SM, Naim T, Chee A, Stapleton DI, et al. Tranilast administration reduces fibrosis and improves fatigue resistance in muscles of mdx dystrophic mice. Fibrogenesis Tissue Repair. 2014;7:1.

31. Murphy KT, Chee A, Gleeson BG, Naim T, Swiderski K, Koopman R, et al. Antibody-directed myostatin inhibition enhances muscle mass and function in tumor-bearing mice. Am j physiol Regulatory, integr comparative physiol. 2011:301:R716-26.

32. Blanco CE, Sieck GC, Edgerton VR. Quantitative histochemical determination of succinic dehydrogenase activity in skeletal muscle fibres. Histochem J. 1988;20:230-43

33. Murphy RM, Mollica JP, Beard NA, Knollmann BC, Lamb GD. Quantification of calsequestrin 2 (CSQ2) in sheep cardiac muscle and Ca2+-binding protein changes in CSQ2 knockout mice. Am J Physiol Heart Circ Physiol. 2011;300:H595-604.

34. Chen SE, Gerken E, Zhang Y, Zhan M, Mohan RK, Li AS, et al. Role of TNF\{alpha\} signaling in regeneration of cardiotoxin-injured muscle. Am j physiol Cell physiol. 2005;289:C1179-87.

35. Cheng M, Nguyen MH, Fantuzzi G, Koh TJ. Endogenous interferon-gamma is required for efficient skeletal muscle regeneration. Am j physiol Cell physiol. 2008;294:C1183-91.

36. Zhang C, Li Y, Wu Y, Wang L, Wang X, Du J. Interleukin-6/signal transducer and activator of transcription 3 (STAT3) pathway is essential for macrophage infiltration and myoblast proliferation during muscle regeneration. J Biol Chem. 2013:288:1489-99.

37. Starr R, Willson TA, Viney EM, Murray LJ, Rayner JR, Jenkins BJ, et al. A family of cytokine-inducible inhibitors of signalling. Nature. 1997;387:917-21.

38. Frost RA, Nystrom GJ, Lang CH. Regulation of IGF-I mRNA and signal transducers and activators of transcription-3 and -5 (Stat-3 and -5 ) by $\mathrm{GH}$ in C2C12 myoblasts. Endocrinology. 2002;143:492-503.

39. Megeney LA, Perry RL, LeCouter JE, Rudnicki MA. bFGF and LIF signaling activates STAT3 in proliferating myoblasts. Dev Genet. 1996;19:139-45.

40. Pijet M, Pijet B, Litwiniuk A, Pajak B, Gajkowska B, Orzechowski A. Leptin impairs myogenesis in C2C12 cells through JAK/STAT and MEK signaling pathways. Cytokine. 2013;61:445-54

41. Zong CS, Chan J, Levy DE, Horvath C, Sadowski HB, Wang LH. Mechanism of STAT3 activation by insulin-like growth factor I receptor. J Biol Chem. 2000;275:15099-105.

42. Forrai A, Boyle K, Hart AH, Hartley L, Rakar S, Willson TA, et al. Absence of suppressor of cytokine signalling 3 reduces self-renewal and promotes differentiation in murine embryonic stem cells. Stem Cells. 2006;24:604-14

43. Bode JG, Nimmesgern A, Schmitz J, Schaper F, Schmitt M, Frisch W, et al. LPS and TNFalpha induce SOCS3 mRNA and inhibit IL-6-induced activation of STAT3 in macrophages. FEBS Lett. 1999:463:365-70.
44. Hong F, Nguyen VA, Gao B. Tumor necrosis factor alpha attenuates interferon alpha signaling in the liver: involvement of SOCS3 and SHP2 and implication in resistance to interferon therapy. FASEB J. 2001;15:1595-7.

45. Stoiber D, Kovarik P, Cohney S, Johnston JA, Steinlein P, Decker T. Lipopolysaccharide induces in macrophages the synthesis of the suppressor of cytokine signaling 3 and suppresses signal transduction in response to the activating factor IFN-gamma. J Immunol. 1999;163:2640-7.

46. Zhang JG, Nicholson SE. Detection of endogenous SOCS1 and SOCS3 proteins by immunoprecipitation and Western blot analysis. Methods $\mathrm{Mol}$ Biol. 2013;967:249-59.

47. Kimura A, Kinjyo I, Matsumura Y, Mori H, Mashima R, Harada M, et al. SOCS3 is a physiological negative regulator for granulopoiesis and granulocyte colony-stimulating factor receptor signaling. J Biol Chem. 2004;279:6905-10.

48. Wong PK, Egan PJ, Croker BA, O'Donnell K, Sims NA, Drake S, et al. SOCS-3 negatively regulates innate and adaptive immune mechanisms in acute IL1-dependent inflammatory arthritis. J Clin Invest. 2006;116:1571-81.

49. Yasukawa $H$, Ohishi M, Mori H, Murakami M, Chinen T, Aki D, et al. IL-6 induces an anti-inflammatory response in the absence of SOCS3 in macrophages. Nat Immunol. 2003;4:551-6.

50. Price FD, von Maltzahn J, Bentzinger CF, Dumont NA, Yin H, Chang NC, et al. Inhibition of JAK-STAT signaling stimulates adult satellite cell function. Nat Med. 2014:20:1174-81.

51. Tierney MT, Aydogdu T, Sala D, Malecova B, Gatto S, Puri PL, et al. STAT3 signaling controls satellite cell expansion and skeletal muscle repair. Nat Med. 2014;20:1182-6.

\section{Submit your next manuscript to BioMed Central and we will help you at every step:}

- We accept pre-submission inquiries

- Our selector tool helps you to find the most relevant journal

- We provide round the clock customer support

- Convenient online submission

- Thorough peer review

- Inclusion in PubMed and all major indexing services

- Maximum visibility for your research

Submit your manuscript at www.biomedcentral.com/submit
) Biomed Central 